Pacific Journal of Mathematic 


\section{COMMUTANTS OF SOME HAUSDORFF MATRICES}

\section{B. E. RHOADES}

Let $B(c)$ denote the Banach algebra of bounded operators over $c$, the space of convergent sequences. Let $\Gamma$ and $\Delta$ denote the subalgebras of $B(c)$ consisting, respectively, of conservative and conservative triangular infinite matrices, and $C$ the Cesaro matrix of order one. In this paper we investigate $\operatorname{Com}(C)$ in $\Gamma$ and $B(c), \operatorname{Com}(H)$ in $\Gamma$ and $B(c)$ for certain Hausdorff matrices $H$, and some related questions.

Let $B(c)$ denote the Banach algebra of bounded operators over $c$, the space of convergent sequences. Let $\Gamma$ and $\Delta$ denote the subalgebras of $B(c)$ consisting, respectively, of conservative and conservative triangular infinite matrices. It is well known (see, e.g. [3, p. 77]) that the commutant of $C$, the Cesaro matrix of order one, in $\Delta$ is the family $\mathscr{H}$ of conservative Hausdorff matrices. The same proof yields the result that if $H$ is any conservative Hausdorff triangle with distinct diagonal elements, then $\operatorname{Com}(H)=\mathscr{H}$ in $\Delta$. In this paper we investigate $\operatorname{Com}(C)$ in $\Gamma$ and $B(c), \operatorname{Com}(H)$ in $\Gamma$ and $B(c)$ for certain Hausdorff matrices $H$, and some related questions.

The spaces of bounded, convergent, and absolutely convergent sequences shall be denoted by $m, c$, and $l$. $U$ will denote the unilateral shift, and we shall use $A \leftrightarrow B$ to indicate that the operators $A$ and $B$ commute. An infinite matrix $A$ is said to be triangular if it has only zero entries above the main diagonal, and a triangle if it is triangular and has no zeros on the main diagonal. An infinite matrix $A$ is conservative; i.e., $A: c \rightarrow c$ if and only if

$$
\|A\|=\sup _{n} \sum_{k}\left|a_{n k}\right|<\infty, \quad a_{k}=\lim _{n} a_{n k}
$$

exists for each $k$, and $\lim _{n} \sum_{k} a_{n k}$ exists.

The proof $[2$, p. 249] that $\operatorname{Com}(C)=\mathscr{H}$ in $\Delta$, uses the associativity of matrix multiplication. If $\operatorname{Com}(C)$ is to remain unchanged in the larger algebra $\Gamma$, it is necessary that $\operatorname{Com}(C)$ contain only triangular matrices. We are thus led to the following result, where $e_{k}$ denotes the coordinate sequence with $a 1$ in the $k$ th position and zeros elsewhere.

THEOREM 1. Let $A$ be a conservative triangle, $B$ an infinite matrix with finite norm, $B \leftrightarrow A$. Then $B$ is triangular if and only if 


$$
t\left(A-a_{n n} I\right)=0
$$

and $t \in l$ imply $t$ lies in the span of $\left(e_{0}, e_{1}, \cdots, e_{n}\right), n=0,1,2, \cdots$.

The conditions in (1) are merely a reformulation of the fact that $B$ is triangular. For, if $B \leftrightarrow A$, then we obtain the system

$$
\sum_{j=k}^{\infty} b_{n j} a_{j k}=\sum_{j=0}^{n} a_{n j} b_{j k} ; n, k=0,1,2, \cdots \text {. }
$$

Define $t^{n}=\left\{b_{n k}\right\}_{k=0}^{\infty}, n=0,1,2, \cdots$; i.e., $t^{n}$ is the $n$-th row of $B$. With $n=0$, (2) can be written in the form $t^{\circ}\left(A-a_{o o} I\right)=0$. Thus $b_{o k}=0$ for $k>0$. By induction, one can then show that $b_{n k}=0$ for $k>n$, and hence $B$ is triangular.

To prove the converse, suppose (1) fails to hold for all $n$. Let $N$ be the smallest such $n$. Then (1) has a nonzero solution outside the span of $\left(e_{0}, e_{1}, \cdots, e_{N}\right)$ and $B$ is not triangular.

A matrix $A$ is said to be of type $M$ if it is not a right zero divisor over $l$ : i.e., $t A=0$ and $t \in l$ imply $t=0$. Therefore, an equivalent formulation of (1) is that $\left(U^{*}\right)^{n+1}\left(A-a_{n n} I\right) U^{n+1}$ be of type $M$ for each $n=0,1,2, \cdots$.

Let $\mathscr{D}$ denote the set of conservative Hausdorff triangles with distinct diagonal entries, $\mathscr{A}$ the algebra of all matrices with finite norm.

Corollary 1. Let $H \in \mathscr{D}$. Then $\operatorname{Com}(H)$ in $\Delta=\operatorname{Com}(H)$ in $\Gamma=\operatorname{Com}(H)$ in $\mathscr{A}=\mathscr{C}$ if and only if (1) is satisfied.

The last equality follows from the fact that every Hausdorff matrix with finite norm is automatically conservative.

A matrix $A$ is said to be factorable if $a_{n k}=c_{n} d_{k}$ for each $n$ and $k$. Examples of factorable triangular matrices are $C$, the Hausdorff matrices generated by $\{a /(n+a)\}$ for $a>0$, and the weighted mean methods (see [2, p. 57]).

THEOREM 2. If $A$ is a factorable triangle and $B \leftrightarrow A$ then $B$ is triangular.

Proof. Set $n=k=0$ in (2) to get

$$
\sum_{j=1}^{\infty} b_{0 j} a_{j 0}=0 \text {. }
$$

From (2) with $n=0, k=1$, we have

$$
a_{00} b_{01}=\sum_{j=1}^{\infty} b_{0 j} a_{j 1}=\sum_{j=1}^{\infty} b_{0 j} c_{j} d_{1}=\left(d_{1} / d_{0}\right) \sum_{j=1}^{\infty} b_{0 j} a_{j 0} .
$$


Since $a_{00} \neq 0, b_{01}=0$ from (3). By induction one can show that $b_{n k}=0$ for $k>n$.

Corollary 2. $\operatorname{Com}(C)$ in $\Delta=\operatorname{Com}(C)$ in $\Gamma=\operatorname{Com}(C)$ in $\mathscr{A}=$ $\mathscr{H}$.

Corollary 2 follows immediately from Theorem 2 since $C$ is factorable.

Corollary 3. If $A \in \Delta$, is factorable, and has exactly one zero on the main diagonal, then $B \leftrightarrow A$ implies $B$ is triangular.

Proof. Let $N$ be such that $a_{N N}=0$. If $N>0$, then the proof of Theorem 2 forces $b_{n k}=0$ for $k>n, n<N$. For $k>N, n=N$ in (2) we have

$$
\sum_{j=k}^{\infty} b_{n j} a_{j k}=\sum_{j=0}^{N} a_{N j} b_{j k}=a_{N N} b_{N k}=0
$$

or

$$
-b_{N k} c_{k}=\sum_{j=k+1}^{\infty} b_{N j} c_{j},
$$

since $d_{k} \neq 0$ for $k>N$. The above equation leads to $b_{N k} c_{k}=0$ which implies $b_{N k}=0$. By induction, $b_{n k}=0$ for $n>N, k>n$.

If a factorable triangular matrix $A$ contains at least two zeros on the main diagonal, then $\operatorname{Com}(A)$ in $\Delta$ need not equal $\operatorname{Com}(A)$ in $\Gamma$. This fact is a special case of the following. A necessary condition for any conservative triangle $A$ to satisfy $\operatorname{Com}(A)$ in $\Delta=\operatorname{Com}(A)$ in $\Gamma$ is that $A$ have distinct diagonal entries. For, suppose there exist integers $i, k, k>i \geqq 0$ such that $a_{i i}=a_{k k}$. Then the matrix $\left(U^{*}\right)^{i+1}\left(A-a_{i i} I\right) U^{i+1}$ has a zero on the main diagonal in the $(k-i)$ th position and is therefore not of type $M$.

A necessary condition, therefore, for a conservative Hausdorff matrix $H$ to satisfy $\operatorname{Com}(H)$ in $\Delta=\operatorname{Com}(H)$ in $\Gamma$ is that $H$ have distinct diagonal entries. The condition, however, is not sufficient. Let $A=H+\lambda K$ where $H$ is the Hausdorff matrix generated by $\mu_{n}=(n-a) /(-a)(n+1), a>0, K$ is the compact Hausdorff matrix generated by $\mu_{0}=1, \mu_{n}=0, n>0$, and $\lambda$ is any real number satisfying $-(a+1) / a<\lambda<0$. We shall show that $B=U^{*}\left(A-a_{00} I\right) U$ is not of type $M$. Thus $\operatorname{Com}(A)$ in $\Gamma$ will contain nontriangular matrices.

Let $D$ by the Hausdorff matrix generated be

$$
\nu_{n}=\frac{\lambda(n-\varepsilon)}{-\varepsilon(n+1)}, \quad \text { where } \varepsilon=\lambda / \delta, \delta=-\lambda-1-1 / a .
$$


Since $a_{00}=1+\lambda$, a straightforward calculation verifies that $D$ and $A-a_{00} I$ agree, except for terms in the first column. $B$ is obtained by removing the first row and first column from $A-a_{00} I$. Therefore $B=U^{*} D U$. By Theorem 1 of [4], $D$ is not of type $M$, and a suitable sequence $t$ is $t_{0}=1, t_{n}=(-1)^{n} \varepsilon(\varepsilon-1) \cdots(\varepsilon-n+1) / n ! n>0$. Therefore $B$ is also not of type $M$.

For $\operatorname{Com}(H)$ in $\Delta$ to equal $\operatorname{Com}(H)$ in $\Gamma$ it is not necessary that) the Hausdorff matrix $H$ be a triangle. Set $H=\bar{H}-\mu_{0} I$, when $\bar{H}$ is any conservative Hausdorff matrix such that $\operatorname{Com}(\bar{H})$ in $\Delta=$ $\operatorname{Com}(\bar{H})$ in $\Gamma$.

We shall now examine $\operatorname{Com}(C)$ in $B(c)$.

Let $e$ denote the sequence of all ones. If $T \in B(c)$ then one can define continuous linear functionals $\chi$ and $\chi_{i}$ by $\chi(T)=\lim T e-\sum_{k}$ $\lim \left(T e_{k}\right)$ and $\chi_{i}(T)=(T e)_{i}-\sum_{k}\left(T e_{k}\right)_{i}, i=1,2, \cdots$ (See, e.g., [5, p. 241].) It is known [1, p. 8] that any $T \in B(c)$ has the representation

$$
T x=v \lim x+B x \quad \text { for each } x \in c,
$$

where $B$ is the matrix representation of the restriction of $T$ to $c_{0}$ and $v$ is the bounded sequence $v=\left\{\chi_{i}(T)\right\}$.

The second adjoint of $T$ has the matrix representation

$$
T^{* *}=\left(\begin{array}{cccc}
\chi(T) & a_{1} & a_{2} & \cdots \\
\chi_{1}(T) & b_{11} & b_{12} & \cdots \\
\chi_{2}(T) & b_{21} & b_{22} & \cdots \\
\cdots & \ldots & \ldots & \ldots
\end{array}\right)
$$

where the $a_{i}$ 's occur in the representation of

$\lim \circ T \in c^{*}$ as $(\lim T)(x)=\lim (T x)=\chi(T) \lim x+\sum_{k} a_{k} x_{k}$.

See, e.g., [6, p. 357].

For the matrix $C$, each $\chi_{i}(C)=0,[5, \mathrm{p} .241]$ and $\chi(C)=1$, so that

$$
C^{* *}=\left(\begin{array}{cccc}
1 & 0 & 0 & \cdots \\
0 & 1 & 0 & \ldots \\
0 & \frac{1}{2} & \frac{1}{2} & \ldots \\
\ldots & \ldots & \ldots
\end{array}\right) .
$$

Since $C \leftrightarrow T$ if and only if $C^{* *} \leftrightarrow T^{* *}$, we may use (5) and (6) to obtain $\left(C^{* *} T^{* *}\right)_{00}=\left(T^{* *} C^{* *}\right)_{00}=\chi(T)$, and, for $n>0$,

$$
\left(C^{* *} T^{* *}\right)_{n 0}=\frac{1}{n} \sum_{k=1}^{n} \chi_{k}(T)=\chi_{n}(T)=\left(T^{* *} C^{* *}\right)_{n 0} .
$$


The system (7) yields $\chi_{n}(T)=\chi_{1}(T), n=1,2,3, \cdots$. Thus $v=$ $\chi_{1}(T) e$. Substituting in (4) with $\chi \in c_{0}$ we see that $c$ must commute with $B$. Since $B$ is a matrix and $B \in \mathscr{A}$, we may use Corollary 2 to obtain the following result.

Theorem 3. Let $T \in B(c)$. Then $T \leftrightarrow C$ if and only if $T$ has the form (4) with $v=\chi_{1}(T) e$ and $B \in \mathscr{H}$.

Note added in proof. The hypotheses of Theorem 1 can be modified without changing the details of the proof. For example, if $A$ and $B$ are any two bounded operators over $l^{p}, p>1$, then the conclusion of Theorem 1 holds. In particular, since $C \in B\left(l^{p}\right)$ for $p>1$, we get as a corollary that $\operatorname{Com}(C)$ in $B\left(l^{p}\right)$ consists only of those Hausdorff matrices that belong to $B\left(l^{p}\right)$. Another description of $\operatorname{Com}(C)$ in $B\left(l^{2}\right)$ appears in A. Shields and L. Wallen [Indiana Univ. Math. J., 20 (1971) 777-788].

\section{REFERENCES}

1. H. I. Brown, D. R. Kerr, Jr. and H. H. Stratton, The structure of $B[c]$ and extensions of the concept of conull matrix, Proc. Amer. Math. Soc. 22 (1969) 7-14.

2. G. H. Hardy, Divergent Series, Oxford, 1949.

3. F. Hausdorff, Summationsmethoden und Momentfolgen, I, Math. Zeit., 9 (1921), 74109.

4. B. E. Rhoades, Some Hausdorff matrices not of type M, Proc. Amer. Math. Soc., 15 (1964), 361-365.

5. A. Wilansky, Topological divisors of zero and Tauberian theorems, Trans. Amer. Math. Soc., 113 (1964), 240-251.

6. L Subalgebras of $B(X)$, Proc. Amer. Math. Soc., 29 (1971), 355-360.

Received August 6, 1971.

INDIANA UNIVERSITY 



\section{PACIFIC JOURNAL OF MATHEMATICS}

\section{EDITORS}

\section{H. SAMELSON}

Stanford University

Stanford, California 94305

\section{R. HOBBY}

University of Washington

Seattle, Washington 98105

\section{J. DugundjI}

Department of Mathematics University of Southern California Los Angeles, California 90007

RICHARD ARENS

University of California

Los Angeles, California 90024

\section{ASSOCIATE EDITORS}
E. F. BECKENBACH
B. H. NeumanN
F. WOLF
K. YOSHIDA

\section{SUPPORTING INSTITUTIONS}

\author{
UNIVERSITY OF BRITISH COLUMBIA \\ CALIFORNIA INSTITUTE OF TECHNOLOGY \\ UNIVERSITY OF CALIFORNIA \\ MONTANA STATE UNIVERSITY \\ UNIVERSITY OF NEVADA \\ NEW MEXICO STATE UNIVERSITY \\ OREGON STATE UNIVERSITY \\ UNIVERSITY OF OREGON \\ OSAKA UNIVERSITY
}

\author{
UNIVERSITY OF SOUTHERN CALIFORNIA \\ STANFORD UNIVERSITY \\ UNIVERSITY OF TOKYO \\ UNIVERSITY OF UTAH \\ WASHINGTON STATE UNIVERSITY \\ UNIVERSITY OF WASHINGTON \\ AMERICAN MATHEMATICAL SOCIETY \\ NAVAL WEAPONS CENTER
}

The Supporting Institutions listed above contribute to the cost of publication of this Journal, but they are not owners or publishers and have no responsibility for its content or policies.

Mathematical papers intended for publication in the Pacific Journal of Mathematics should be in typed form or offset-reproduced, (not dittoed), double spaced with large margins. Underline Greek letters in red, German in green, and script in blue. The first paragraph or two must be capable of being used separately as a synopsis of the entire paper. The editorial "we" must not be used in the synopsis, and items of the bibliography should not be cited there unless absolutely necessary, in which case they must be identified by author and Journal, rather than by item number. Manuscripts, in duplicate if possible, may be sent to any one of the four editors. Please classify according to the scheme of Math. Rev. Index to Vol. 39. All other communications to the editors should be addressed to the managing editor, Richard Arens, University of California, Los Angeles, California, 90024.

50 reprints are provided free for each article; additional copies may be obtained at cost in multiples of 50 .

The Pacific Journal of Mathematics is published monthly. Effective with Volume 16 the price per volume (3 numbers) is $\$ 8.00$; single issues, $\$ 3.00$. Special price for current issues to individual faculty members of supporting institutions and to individual members of the American Mathematical Society: $\$ 4.00$ per volume; single issues $\$ 1.50$. Back numbers are available.

Subscriptions, orders for back numbers, and changes of address should be sent to Pacific Journal of Mathematics, 103 Highland Boulevard, Berkeley, California, 94708.

PUBLISHED BY PACIFIC JOURNAL OF MATHEMATICS, A NON-PROFIT CORPORATION

Printed at Kokusai Bunken Insatsusha (International Academic Printing Co., Ltd.), 270, 3-chome Totsuka-cho, Shinjuku-ku, Tokyo 160, Japan. 


\section{Pacific Journal of Mathematics}

\section{Vol. 42, No. $3 \quad$ March, 1972}

Catherine Bandle, Extensions of an inequality by Pólya and Schiffer for vibrating membranes ................................ 543

S. J. Bernau, Topologies on structure spaces of lattice groups.......... 557

Woodrow Wilson Bledsoe and Charles Edward Wilks, On Borel product measures .......................................

Eggert Briem and Murali Rao, Normpreserving extensions in subspaces of

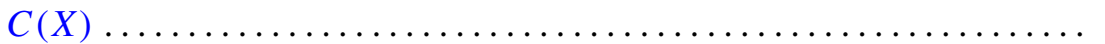

Alan Seymour Cover, Generalized continuation.................. 589

Larry Jean Cummings, Transformations of symmetric tensors .......... 603

Peter Michael Curran, Cohomology of finitely presented groups .......... 615

James B. Derr and N. P. Mukherjee, Generalized quasicenter and

hyperquasicenter of a finite group ...................... 621

Erik Maurice Ellentuck, Universal cosimple isols .................. 629

Benny Dan Evans, Boundary respecting maps of 3-mainfolds .......... 639

David F. Fraser, A probabilistic method for the rate of convergence to the

Dirichlet problem .................................. 657

Raymond Taylor Hoobler, Cohomology in the finite topology and Brauer

groups ..................................... 667

Louis Roberts Hunt, Locally holomorphic sets and the Levi form ........ 681

B. T. Y. Kwee, On absolute de la Vallée Poussin summability............ 689

Gérard Lallement, On nilpotency and residual finiteness in semigroups .... 693

George Edward Lang, Evaluation subgroups of factor spaces........... 701

Andy R. Magid, A separably closed ring with nonzero torsion pic ....... 711

Billy E. Rhoades, Commutants of some Hausdorff matrices ............. 715

Maxwell Alexander Rosenlicht, Canonical forms for local derivations . . . . 721

Cedric Felix Schubert, On a conjecture of L. B. Page ................ 733

Reinhard Schultz, Composition constructions on diffeomorphisms of $S^{p} \times S^{q}$

J. P. Singhal and H. M. (Hari Mohan) Srivastava, A class of bilateral generating functions for certain classical polynomials ....

Richard Alan Slocum, Using brick partitionings to establish conditions which insure that a Peano continuum is a 2-cell, a 2-sphere or an annulus...

James F. Smith, The p-classes of an $H^{*}$-algebra ...

Jack Williamson, Meromorphic functions with negative zeros and positive

poles and a theorem of Teichmuller ................. 